\title{
Pathophysiological effects of androgens on the female vascular system
}

Tori Stone ${ }^{1,2}$ and Nina S. Stachenfeld ${ }^{1,2^{*}}$ (D)

\begin{abstract}
Sex hormones and their respective receptors affect vascular function differently in men and women, so it is reasonable to assume they play a role in the sex differences in cardiovascular disease states. This review focuses on how the effects of testosterone on arterial vessels impact the female vasculature. In women with androgen-excess polycystic ovary syndrome, and in transgender men, testosterone exposure is associated with high blood pressure, endothelial dysfunction, and dyslipidemia. These relationships suggest that androgens may exert pathophysiological effects on the female vasculature, and these effects on the female vasculature appear to be independent from other co-morbidities of cardiovascular disease. There is evidence that the engagement of androgens with androgen receptor induces detrimental outcomes in the female cardiovascular system, thereby representing a potential causative link with sex differences and cardiovascular regulation. Gender affirming hormone therapy is the primary medical intervention sought by transgender people to reduce the characteristics of their natal sex and induce those of their desired sex. Transgender men, and women with androgen-excess polycystic ovary syndrome both represent patient groups that experience chronic hyperandrogenism and thus lifelong exposure to significant medical risk. The study of testosterone effects on the female vasculature is relatively new, and a complex picture has begun to emerge. Long-term research in this area is needed for the development of more consistent models and controlled experimental designs that will provide insights into the impact of endogenous androgen concentrations, testosterone doses for hormone therapy, and specific hormone types on function of the female cardiovascular system.
\end{abstract}

Keywords: Transgender, Trans men, Testosterone, Endothelial function, Blood pressure

\section{Introduction}

Most studies on vascular dysfunction have been conducted on male subjects, in part due to a general assumption (in the early part of the twentieth century) that women were at low risk for generalized cardiovascular diseases. Further, it was generally assumed that physiological responses in women would be similar to those of men. Excluding women from research studies resulted in an overall failure to recognize the important and differential effects of reproductive hormones on the

\footnotetext{
* Correspondence: nina.stachenfeld@yale.edu

${ }^{1}$ John B. Pierce Laboratory, 290 Congress Ave, New Haven, CT 06510, USA ${ }^{2}$ Department of Obstetrics, Gynecology and Reproductive Sciences, Yale School of Medicine, New Haven, CT, USA
}

female cardiovascular system. In 1993, the US Congress passed the NIH Revitalization Act (https:/grants.nih. gov/grants/funding/women_min/guidelines.htm) directing the National Institutes of Health to ensure the inclusion of women in clinical research unless "a clear and compelling rationale and justification establishes to the satisfaction of the relevant Institute/Center Director that inclusion is inappropriate with respect to the health of the subjects or the purpose of the research." Cardiovascular disease is recognized as the leading cause of mortality in both men and women in the USA [1]. Moreover, the influence of sex hormones in cardiovascular health is complex and related to age, environment, sex differences in the tissues exposed, and, in the case of

(c) The Author(s). 2020 Open Access This article is licensed under a Creative Commons Attribution 4.0 International License, which permits use, sharing, adaptation, distribution and reproduction in any medium or format, as long as you give appropriate credit to the original author(s) and the source, provide a link to the Creative Commons licence, and indicate if changes were made. The images or other third party material in this article are included in the article's Creative Commons licence, unless indicated otherwise in a credit line to the material. If material is not included in the article's Creative Commons licence and your intended use is not permitted by statutory regulation or exceeds the permitted use, you will need to obtain permission directly from the copyright holder. To view a copy of this licence, visit http://creativecommons.org/licenses/by/4.0/ The Creative Commons Public Domain Dedication waiver (http://creativecommons.org/publicdomain/zero/1.0/) applies to the data made available in this article, unless otherwise stated in a credit line to the data. 
exogenous hormones, the route of administration. The current review highlights the impact on the female vascular system when exposed to high levels of androgens.

\section{Androgens}

In men, testosterone is synthesized in testicular Leydig cells and secreted by the testes. Approximately $10 \%$ of testosterone is converted via 5-alpha reductase to the potent dihydrotestosterone (DHT). This conversion to DHT primarily occurs in target tissues such as prostate, seminal vesicles, and hair follicles, and then binds to the androgen receptor (AR) specific to that tissue. The adrenals in both men and women secrete small amounts of testosterone that is quickly converted to estrogen via aromatase. In women, the ovaries also produce small amounts of testosterone, most of which are quickly aromatized to estrogen. In both men and women, the aromatization of testosterone to estrogen is mainly a peripheral effect taking place in a number of tissues throughout the body, including blood vessels, brain, fat, skin, and bone. Androgens regulate gene transcription when ligand-activated and also may induce rapid activation via kinase signaling cascades and mechanisms independent of transcription [2-5], such as activation of intracellular $\mathrm{Ca}^{2+}$ [5], MAPK [3], Akt [2], and PKA/PKC [6] (Fig. 1). Androgen receptors are expressed in cells throughout the vascular system, including endothelial cells [8] and vascular smooth muscle cells [9]. The AR primarily mediates androgenic effects on the endothelium, and some androgen effects on the vascular system are mediated indirectly through estrogen [10] after testosterone conversion by aromatase [8]. Androgen actions on the endothelium are often mediated by NO [11-13]. These actions vary significantly in men because both estradiol exposure and aromatase levels fluctuate widely.

\section{Androgens in females}

Estrogens may play a cardioprotective role at certain stages of life in females [14-16], meaning that women with high estrogen exposure have a lower incidence of cardiovascular disease or coronary artery disease (CAD) compared to age-matched men [15]. Androgens appear to induce unfavorable responses in the female vascular system [17, 18]. Engagement of androgens and the AR leads to impaired agonist-triggered endothelial $\mathrm{NO}$ release in women [19]. For example, high circulating androgen levels in women, such as in androgen-excess PCOS (AE-PCOS), is associated with high circulating
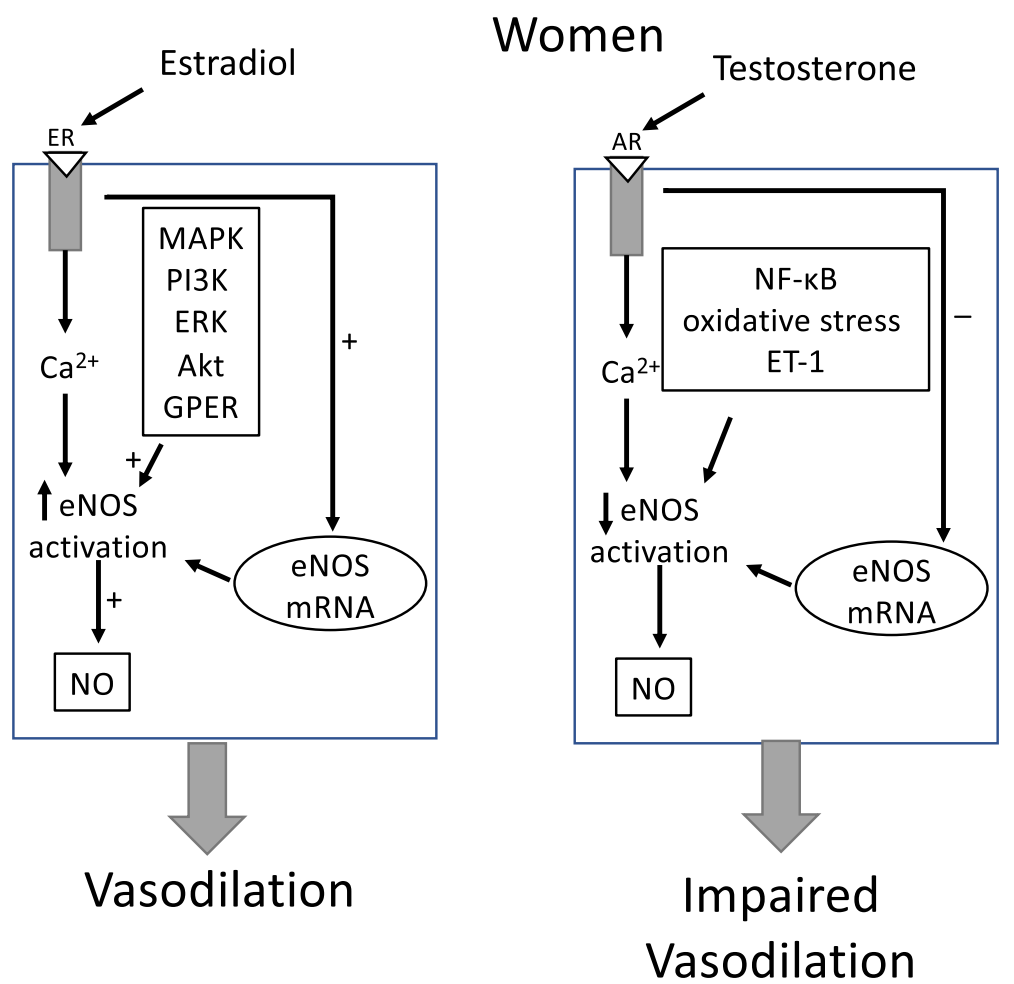

Fig. 1 Sex differences in the signal transduction pathways of eNOS activation in endothelial cells by testosterone and the subsequent vascular response. Testosterone is generally thought to increase nitric oxide (NO) availability through genomic and non-genomic pathways in men. Testosterone works through a separate pathway in women resulting in reduced NO availability and impaired vasodilation. Androgen receptor (AR), endothelial NO synthase (eNOS), extracellular signal-regulated kinase (ERK), phosphatidylinositol 3-kinase (PI3K), Akt (protein kinase B), G protein-coupled estrogen receptor 1 (GPR30 agonist, G-1). From Stanewicz et al. [7], with permission 
inflammatory cytokines, oxidative stress, and NF- $\mathrm{kB}$ activation [20], all of which impair NO release and lead to endothelial dysfunction [21] and mild hypertension [22]. Androgen exposure is associated with endothelial dysfunction in women, including elevated ET-1 levels, independent of insulin resistance, obesity, or fertility status [19]. Some [23-25], but not all [26, 27] studies suggest that as women age and enter perimenopause, when both androgens and estrogens are fluctuating [28], androgens are more pronounced and are associated with coronary artery calcification and carotid intima-media thickness.

The sex differences in vascular function are well recognized and impact clinical presentation, pathophysiology, treatment, and response to treatment [29]. Sex hormones affect vascular function differently in men and women and, therefore, likely contribute to these differences in vascular function $[7,30,31]$. There is evidence that the engagement of androgens and the AR represent a causative link between sex differences and vascular function and induce detrimental outcomes on the female vascular system [31-36]. These effects are in contrast to men, in whom androgen effects can be positive or negative depending on the physiological environment and factors that disrupt it [5]. Androgens can increase reactive oxygen species and decrease NO bioavailability in females, so likely contribute to increases in blood pressure [37].

\section{Androgen-excess polycystic ovary syndrome}

Polycystic ovary syndrome (PCOS), the most common reproductive endocrinopathy affecting $\sim 1$ in 10 women, is the most common cause of infertility in women. Approximately, $75 \%$ of women with PCOS have the more severe endocrine and metabolic PCOS phenotype, AEPCOS, that is dominated by clinical and biochemical manifestations of hyperandrogenism. The pathophysiology involves dysregulation of a number of endocrine signals, including altered pulsatility of hypothalamic gonadotropin-releasing hormone $(\mathrm{GnRH})$ from the arcuate nucleus, resulting in altered secretion of the pituitary gonadotropins luteinizing hormone (LH) and folliclestimulating hormone (FSH). This disordered hypothalamic function is associated with excess production of androgens under the influence of both elevated LH and excess insulin as well as disordered insulin action in target tissues and failure of ovarian folliculogenesis due to the altered gonadotropin signaling and hyperandrogenemic milieu. Ovaries of AE-PCOS women are replete with oocytes containing immature follicles, but mechanisms that underlie the dynamics of normal follicular growth and egg maturation are disordered. Thus the "cysts" of AE-PCOS ovaries represent arrested follicles that contain immature eggs. Finally, in addition to androgen excess, AE-PCOS is a state of progesterone deficiency resulting from chronic failure to achieve ovulation.
The overexposure to androgens is considered the key disruption influencing the clinical features of AE-PCOS. The mechanisms responsible for vascular dysfunction in AE-PCOS are currently unknown, but research also points to the chronic excess androgen milieu [38-41]. The androgenic effects on cardiovascular risk are already apparent in young women with AE-PCOS [20, 21, 42-44] and characterized by endothelial dysfunction [45-48]. Endothelial dysfunction is an early sign of atherosclerosis, hypertension, and diabetes and usually driven by impaired agonist-triggered endothelial NO release [49]. Impairments in agonist-triggered endothelial $\mathrm{NO}$ release are evident in women with AE-PCOS and exacerbated by increased circulating inflammatory cytokines, oxidative stress, and NF- $\kappa B$ activation [20] that contribute to the endothelial dysfunction [21] and result in mild hypertension [22]. Thus, chronic hypertension and endothelial dysfunction [21] are prevalent in young women with AEPCOS [50]. The altered vascular function is concomitant with a spectrum of other covert risk markers of CAD, including obesity, insulin resistance, an atherogenic lipid profile, and proinflammatory milieu [50]. Endothelin-1 is one of several circulating indicators of endothelial injury $[51,52]$ and poor endothelial function [53]. In our studies in women with AE-PCOS, we demonstrated elevated ET1 compared to control obese, insulin-resistant women. We also demonstrated that short-term (4-7 days) of androgen suppression with a GnRH antagonist reduced ET1 (Fig. 2) [21, 54]. Finally, administering methyltestosterone while continuing the GnRH antagonist had little impact on ET-1 levels in either group (Fig. 2) [40]. From our results in women with AE-PCOS, we concluded that androgens drove dysfunction in the ET-1 system and the associated poor endothelial dysfunction. From these same studies, we also showed an increase in ET-1 during GnRH antagonist administration in our control obese, insulinresistant group without AE-PCOS, likely due to estrogen suppression (Fig. 2) [40].

Although the prominent phenotype of young women with AE-PCOS manifests a spectrum of covert CAD risk markers (including obesity, insulin resistance, hypertension, an atherogenic lipid profile, and a proinflammatory milieu), we hypothesized that their poor endothelial mediated vascular function is driven by elevated androgen exposure. Recent data from our laboratory supported this hypothesis when we demonstrated poor vascular function in lean women with AE-PCOS (Fig. 3) [38]. In these studies, endothelial function was compromised in lean, insulin-sensitive women with AE-PCOS indicating the relation of AE-PCOS to vascular dysfunction is independent of insulin resistance, obesity, and fertility status [19], and supporting our hypothesis that endothelial dysfunction in AE-PCOS was a consequence of elevated androgen exposure. These data provided strong evidence 

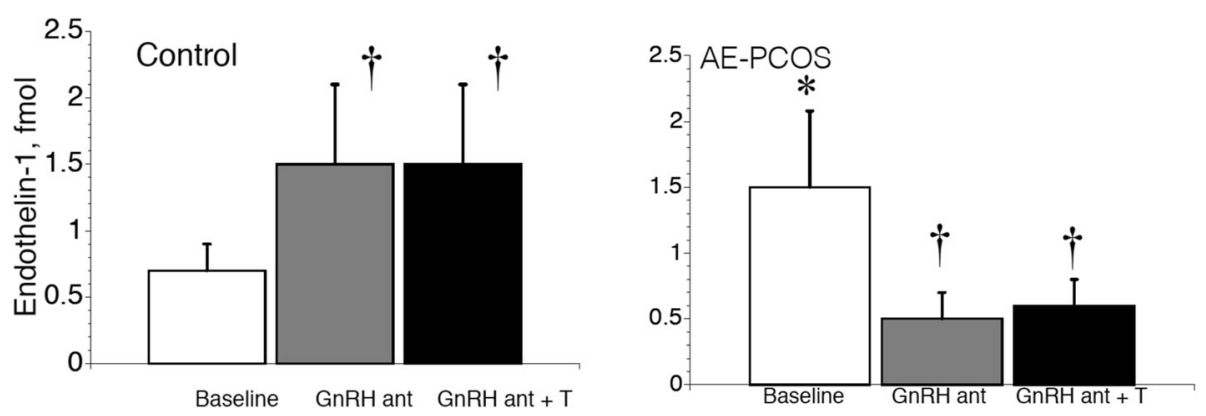

Fig. 2 Plasma endothelin-1 ( $\left.P_{[E T-1]}\right)$ concentration increases in control women but decreases in women with androgen excess-polycystic ovary syndrome (AE-PCOS) during testosterone (T) suppression with a gonadotropin releasing hormone antagonist (GnRH ant). Asterisk indicates greater baseline $\mathrm{P}_{[\mathrm{ET}-1]}$ in AE-PCOS compared to control. Dagger indicates changes in $\mathrm{P}_{[\mathrm{ET}-1]}$ during $\mathrm{T}$ suppression and $\mathrm{T}$ administration, $P<0.05$. Data from Wenner et al. [40], with permission

that elevated androgen levels have a negative impact on endothelial function and overall vascular function in women with AE-PCOS.

We have also studied the impact of testosterone effects on the autonomic control of blood pressure in women with AE-PCOS. The arterial baroreflex is a key homeostatic mechanism that regulates fluctuations in blood pressure that occur with each heartbeat. Women with AE-PCOS show poor baroreflex function [55]. Further, AE-PCOS is also associated with impaired cardiac (cardiovagal) baroreflex [56], which contributes to sympathovagal dysfunction during standing [57] and impaired autonomic control [58]. In general, plasma testosterone levels and peripheral, i.e., muscle sympathetic neural activity (MSNA), are positively correlated [59]. Women with AE-PCOS also demonstrate increased spontaneous MSNA [60] and resting blood pressure versus healthy controls, as well as decreased sympathetic baroreflex gain-i.e., the slope of the relationship between MSNA and blood pressure, further demonstrating impaired autonomic control of blood pressure in women with AE-PCOS [55]. It follows that elevated testosterone in women may impair sympathetic baroreflex control of arterial blood pressure. In support of this hypothesis, the testosterone-MSNA relationship is more powerful in lean compared to obese women with AE-PCOS [60, 61]. These findings also indicate that testosterone is an independent predictor of MSNA in AE-PCOS [60, 61].

\section{Transgender men}

While studies on AE-PCOS have successfully demonstrated the effects of chronic androgen exposure on endothelial function and blood pressure regulation in women exposed to chronically high androgens, there are many confounding cardiovascular disease risk factors associated with PCOS. In contrast, young, healthy transgender men receive levels of testosterone $(40-100 \mathrm{mg} /$ week) to achieve male physiologic levels (400-1000 ng/ $\mathrm{mL}$ testosterone) during gender-affirming hormone therapy (HT) to achieve female-to-male gender transition, and doses are adjusted to address the patients' goals and responses [48, 62]. Increasing testosterone exposure creates extremely high androgen exposure to the female
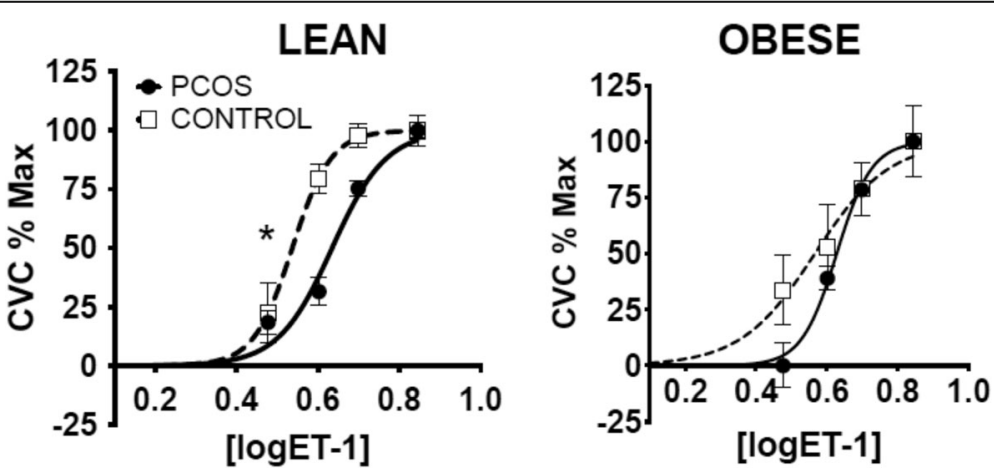

Fig. 3 Dose-response curves during cutaneous microdialysis perfusions of low dose endothelin-1 (ET-1) in lean (left) and obese (right) women with androgen excess polycystic ovary syndrome (AE-PCOS) and control subjects. Percent maximal cutaneous vasodilation (CVC \%Max). Asterisk indicates difference from Control within lean BMl group. Data are presented as means \pm SEM. From Usselman et al. [38], with permission 
cardiovascular system. Thus, research on the impact of these male physiologic doses of androgens on female cardiovascular and other systems is needed and provides an opportunity to isolate the impact of testosterone on vascular function in the female cardiovascular system.

Approximately 1.4 million people in the USA $(0.6 \%$ of the population) identify as transgender [63] or having a current gender identity that differs from the sex assigned at birth. Cisgender individuals have a gender identity the same as the sex assigned at birth. Transgender men are persons assigned female at birth with a male gender identity. Gender affirming hormone therapy to reduce characteristics of their natal sex and induce those of their desired sex is the primary medical intervention sought by transgender people. While HT is recognized by the World Professional Association for Transgender Health as medically necessary [64], there are significant medical risks associated with HT [65], including potential cardiovascular risk [66-68]. Reduced ovarian hormones concomitant with increased testosterone during HT is associated with increased systolic blood pressure [48], dyslipidemia [48, 66], endothelial dysfunction [48], and thrombosis risk markers in young trans men [69]. Further, attention to the androgen effects on the CV system in trans men is especially important because HT continues throughout their lifetime into old age.

Many transgender individuals begin HT at an early age when the overall risk for cardiovascular events is still low. Therefore, it is important during HT to evaluate biomarkers and risk factors that predict cardiovascular disease later in life. Importantly, even in these younger trans men cohorts, HT is associated with increased systolic blood pressure in some [70-72] but not all studies $[73,74]$, and is also associated with increased triglycerides (TG) [72, 74], LDL-cholesterol and decreased HDLcholesterol $[66,71]$. A recent meta-analysis revealed that in a female-to-male transgender population, testosterone administration increased serum TG and LDL-cholesterol and decreased HDL-cholesterol at 3, 6, and 24 months
[66]. Cardiovascular morbidity is not yet apparent in these young trans men [67], and these studies did not follow subjects to an age when risks of CAD are known to accelerate.

In a recent study in our laboratory, systolic and mean blood pressures were slightly but not statistically higher in trans men (20-33 years) undergoing HT ([ $\mathrm{T}_{[\text {Total }]} 196$ $1100 \mathrm{ng} / \mathrm{mL}$ ) relative to cisgender females (18-36 years) (Fig. 4, $P=0.07$ ) [48]. It is difficult to tell from these data whether these increases portend a risk of future organ damage or are a harbinger for future CAD [75] because DBP was not increased. Mild hypertension in trans men is not currently treated. Further study in these areas is crucial because even mild chronic elevations in blood pressure can result in organ damage, leading to frank hypertension. In this same study, we demonstrated markedly diminished endothelial function in trans men compared to cisgender women (Fig. 5) [48] and endothelial dysfunction is a key predictor of atherosclerosis. Again, we see an important sex difference because testosterone therapy decreases atherosclerotic CAD risk in older, hypogonadal cisgender men $[77,78]$, which has been attributed to improved or disrupted AR signaling pathways that govern lipid/lipoprotein metabolism [79].

Androgen administration in trans men is also associated with dyslipidemia [71, 80-82]. An observational study (45 months) compared lipid profiles in trans men receiving testosterone and trans men not taking HT [71]. Trans men taking HT had significantly less favorable lipid profiles, such that HDL-C levels were lower, total cholesterol was higher, and triglyceride levels were nearly double compared to controls. Similar results were reported in a separate observational study [80] and have also been confirmed in meta-analyses [81, 82].

While similar lipid abnormalities in women with AEPCOS have also been demonstrated, these are more difficult to interpret and likely result from the combined effects of hyperandrogenism, obesity, and insulin resistance that are present with AE-PCOS. The interdependence of
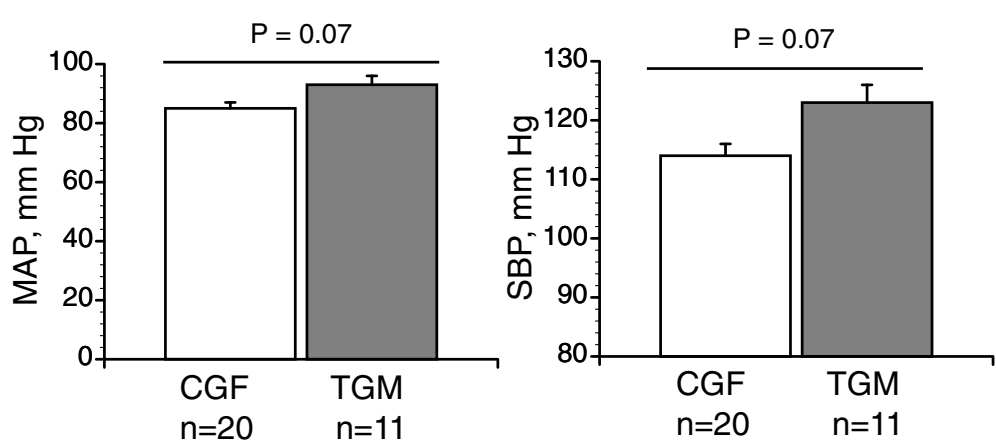

Fig. 4 Trans men exhibit mild hypertension compared to cisgender females. Systolic blood pressure, SBP: $123 \pm 3$ vs. $114 \pm 2 \mathrm{~mm} \mathrm{Hg}$, and mean blood pressure, MAP: $93 \pm 3$ vs. $85 \pm 2 \mathrm{~mm} \mathrm{Hg}$ (mean \pm SEM). Blood pressure was taken supine by auscultation, following 15 min of rest. From Gulanski et al. [48], with permission 

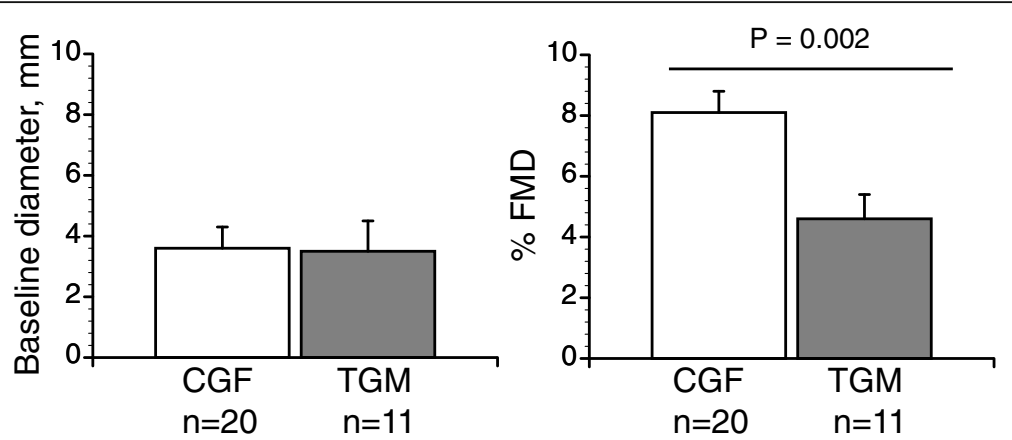

Fig. 5 Trans men exhibit diminished endothelial function compared to cisgender females. Flow mediated vasodilation (\%FMD): $4.5 \pm 0.9$ vs. $8.1 \pm$ $1.0 \%$ (mean \pm SEM). We used a standard protocol [76]. In each protocol, the subject lay supine, ultrasound brachial artery measures were recorded at baseline for $3 \mathrm{~min}$. Forearm ischemia was then induced by rapidly inflating a blood pressure cuff to supra-systolic pressure (i.e., $\geq$ 160-180 mm Hg) for $5 \mathrm{~min}$. Brachial artery measures were obtained continuously for 3 min following cuff deflation. FMD analysis is described in Gulanski et al. [48], with permission

androgen and insulin contributions to lipid metabolism is recognized [79], but these effects can be independent in women with androgen excess [83], suggesting an important role for androgen exposure in the AE-PCOS women as well. That said, androgen control of lipid metabolism is not well understood in women and could also rely on estrogen action.

\section{Conclusions}

Our data and others support an association between hyperandrogenism and mild elevations in blood pressure, endothelial dysfunction, and dyslipidemia in trans men and women with AE-PCOS. Despite the evidence that androgen exposure during gender-affirming hormone therapy is associated with mild hypertension, endothelial dysfunction, and dyslipidemia in trans men, the lack of long-term studies and infrequent follow-up measures for existing studies has led to uncertainty about the effects of HT on cardiovascular outcomes [80]. Cardiovascular markers are not always treated in trans men or AE-PCOS, leaving these cohorts at greater risk for cardiovascular events and future CAD, and even mild hypertension can be detrimental to the cardiovascular system when chronic. AE-PCOS is often diagnosed in the early teenage years, and gender transition often occurs at a young age. In both cases, androgen exposure will last for many years. Long-term and follow-up research are needed to develop guidelines for cardiovascular outcomes during HT and support health and longevity in trans men.

\section{Perspectives and significance}

Despite the work presented in this review, the long-term health risks of testosterone exposure on the female vascular system and the impact of testosterone in women with AE-PCOS, and in trans men receiving androgens, remain underappreciated. In particular, attention to cardiovascular and metabolic risk factors should be integral to the care of these cohorts. The high, chronic androgen therapy environment in trans men provides a unique opportunity to study the impact of long-term androgen exposure on the female vascular system. This is especially important because the elevated androgens in trans men remain throughout their lifetime, continuing into older age when CAD risk develops independent of hormone exposure.

\section{Abbreviations}

Akt: Protein kinase B; AE-PCOS: Androgen excess-polycystic ovary syndrome; AR: Androgen receptor; BMI: Body mass index; CAD: Coronary artery disease; CVC \%Max: Percent maximal cutaneous vasodilation; ERK: Extracellular signalregulated kinases; ET-1: Endothelin-1; FMD: Flow-mediated vasodilation; GnRH ant: Gonadotropin-releasing hormone antagonist; GPR30 agonist G1: G protein-coupled estrogen receptor 1; HDL-cholesterol: High-density lipoprotein cholesterol; HT: Hormone therapy; LDL-cholesterol: Low-density lipoprotein cholesterol; MAPK: Mitogen-activated protein kinase; MSNA: Muscle sympathetic neural activity; NF-KB: Nuclear factor kappa-lightchain-enhancer of activated B cells; NO: Nitric oxide; PCOS: Polycystic ovary syndrome; PI3K: Phosphatidylinositol 3-kinase; PKA/PKC: Protein kinase A/ protein kinase C; SBP: Systolic blood pressure; TG: Triglycerides; Trans men: Female-to-male transgender individuals

\section{Acknowledgements}

N/A

\section{Disclosures}

No conflicts of interest, financial, or otherwise are declared by the authors.

\section{Authors' contributions}

T.S. and N.S.S. edited and revised the manuscript and approved the final version of the manuscript and contributed equally.

\section{Funding}

Funding this work was supported by the National Institutes of Health $(\mathrm{NIH})$ Grant HL135089.

\section{Availability of data and materials N/A}

Ethics approval and consent to participate N/A 


\section{Consent for publication}

The authors consent for the Biology of Sex Differences to publish this material.

\section{Competing interests}

The authors declare that they have no competing interests.

Received: 7 February 2020 Accepted: 20 July 2020

Published online: 29 July 2020

\section{References}

1. Benjamin EJ, Blaha MJ, Chiuve SE, Cushman M, Das SR, Deo R, et al. Heart disease and stroke statistics-2017 update: a report from the American Heart Association. Circulation. 2017;135:e146-603.

2. Baron S, Manin M, Beaudoin C, Leotoing L, Communal $Y$, Veyssiere $G$, et al. Androgen receptor mediates non-genomic activation of phosphatidylinositol 3-OH kinase in androgen-sensitive epithelial cells. J Biol Chem. 2004;279:14579-86.

3. Heinlein CA, Chang C. The roles of androgen receptors and androgenbinding proteins in nongenomic androgen actions. Mol Endocrinol. 2002;16: 2181-7

4. Pihlajamaa $P$, Sahu B, Jänne $O A$. Determinants of receptor- and tissuespecific actions in androgen signaling. Endocr Rev. 2015;36:357-84.

5. Boese AC, Kim SC, Yin KJ, Lee JP, Hamblin MH. Sex differences in vascular physiology and pathophysiology: estrogen and androgen signaling in health and disease. Am J Physiol Heart Circ Physiol. 2017;313:H524-H45.

6. Foradori CD, Weiser MJ, Handa RJ. Non-genomic actions of androgens. Front Neuroendocrinol. 2008;29:169-81.

7. Stanhewicz AE, Wenner MM, Stachenfeld NS. Sex differences in endothelial function important to vascular health and overall cardiovascular disease risk across the lifespan. Am J Physiol-Heart Circulatory Physiol. 2018;315:H1569H88.

8. Torres-Estay V, Carreno DV, San Francisco IF, Sotomayor P, Godoy AS, Smith GJ. Androgen receptor in human endothelial cells. J Endocrinol. 2015;224: R131-7

9. Lopes RAM, Neves KB, Pestana CR, Queiroz AL, Zanotto CZ, Chignalia AZ, et al. Testosterone induces apoptosis in vascular smooth muscle cells via extrinsic apoptotic pathway with mitochondria-generated reactive oxygen species involvement. Am J Physiol-Heart Circ Physiol. 2014;306:H1485-H94.

10. Nettleship JE, Jones TH, Channer KS, Jones RD. Physiological testosterone replacement therapy attenuates fatty streak formation and improves highdensity lipoprotein cholesterol in the Tfm mouse. Circulation. 2007;116:2427.

11. Bernini G, Versari D, Moretti A, Virdis A, Ghiadoni L, Bardini M, et al. Vascular reactivity in congenital hypogonadal men before and after testosterone replacement therapy. J Clin Endocrinol Metab. 2006;91:1691-7.

12. Hutchison SJ, Sudhir K, Chou TM, Sievers RE, Zhu BQ, Sun YP, et al. Testosterone worsens endothelial dysfunction associated with hypercholesterolemia and environmental tobacco smoke exposure in male rabbit aorta. J Am Coll Cardiol. 1997:29:800-7.

13. Kataoka T, Hotta Y, Maeda Y, Kimura K. Testosterone deficiency causes endothelial dysfunction via elevation of asymmetric dimethylarginine and oxidative stress in castrated rats. J Sex Med. 2017;14:1540-8.

14. Harman SM. Combined estrogen plus progestin may reduce coronary heart disease risk after 5 years of use in postmenopausal women starting treatment within 10 years of menopause. Evidence Based Medicine. 2010;15: 69-70.

15. Iorga A, Cunningham CM, Moazeni S, Ruffenach G, Umar S, Eghbali M. The protective role of estrogen and estrogen receptors in cardiovascular disease and the controversial use of estrogen therapy. Biol Sex Differ. 2017:8:33.

16. Usselman CW, Stachenfeld NS, Bender JR. The molecular actions of oestrogen in the regulation of vascular health. Exp Physiol. 2016;101:356-61.

17. Liu PY, Death AK, Handelsman DJ. Androgens and cardiovascular disease Endocr Rev. 2003;24:313-40.

18. Dixit KCS, Wu J, Smith LB, Hadoke PWF, Wu FCW. Androgens and coronary artery disease. In: De Groot LJ, Chrousos G, Dungan K, Feingold KR, Grossman A, Hershman JM, et al., editors. Endotext. South Dartmouth (MA)2000

19. Calderon-Margalit R, Schwartz SM, Wellons MF, Lewis CE, Daviglus ML, Schreiner PJ, et al. Prospective association of serum androgens and sex hormone-binding globulin with subclinical cardiovascular disease in young adult women: the "Coronary Artery Risk Development in Young Adults" women's study. J Clin Endocrinol Metab. 2010;95:4424-31.
20. Diamanti-Kandarakis E. Polycystic ovarian syndrome: pathophysiology, molecular aspects and clinical implications. Expert Rev Mol Med. 2008;10:e3.

21. Wenner MM, Haddadin AS, Taylor HS, Stachenfeld NS. Mechanisms contributing to low orthostatic tolerance in women: the influence of oestradiol. J Physiol. 2013.

22. Wu CC, Cheng J, Zhang FF, Gotlinger KH, Kelkar M, Zhang Y, et al. Androgen-dependent hypertension is mediated by 20-hydroxy-5,8,11,14eicosatetraenoic acid-induced vascular dysfunction: role of inhibitor of kappaB Kinase. Hypertension. 2011;57:788-94.

23. Ouyang P, Vaidya D, Dobs A, Golden SH, Szklo M, Heckbert SR, et al. Sex hormone levels and subclinical atherosclerosis in postmenopausal women: the multi-ethnic study of atherosclerosis. Atherosclerosis. 2009;204:255-61.

24. Creatsa M, Armeni E, Stamatelopoulos K, Rizos D, Georgiopoulos G, Kazani $M$, et al. Circulating androgen levels are associated with subclinical atherosclerosis and arterial stiffness in healthy recently menopausal women. Metabolism. 2012;61:193-201.

25. Bernini GP, Sgro' M, Moretti A, Argenio GF, Barlascini CO, Cristofani R, et al. Endogenous androgens and carotid intimal-medial thickness in women. J Clin Endocrinol Metab. 1999;84:2008-12

26. Calderon-Margalit R, Siscovick D, Merkin SS, Wang E, Daviglus ML, Schreiner PJ, et al. Prospective association of polycystic ovary syndrome with coronary artery calcification and carotid-intima-media thickness: the coronary artery risk development in young adults women's study. Arterioscler Thromb Vasc Biol. 2014;34:2688-94.

27. Kische H, Gross S, Wallaschofski H, Volzke H, Dorr M, Nauck M, et al. Serum androgen concentrations and subclinical measures of cardiovascular disease in men and women. Atherosclerosis. 2016;247:193-200.

28. Laughlin GA, Barrett-Connor E, Kritz-Silverstein D, von Muhlen D. Hysterectomy, oophorectomy, and endogenous sex hormone levels in older women: the Rancho Bernardo study. J Clin Endocrinol Metab. 2000;85:645-51.

29. Rosano GM, Sheiban I, Massaro R, Pagnotta P, Marazzi G, Vitale C, et al. Low testosterone levels are associated with coronary artery disease in male patients with angina. Int J Impot Res. 2007;19:176-82.

30. Vitale C, Mendelsohn ME, Rosano GM. Gender differences in the cardiovascular effect of sex hormones. Nat Rev Cardiol. 2009;6:532-42.

31. Sieveking DP, Lim P, Chow RWY, Dunn LL, Bao S, McGrath KCY, et al. A sexspecific role for androgens in angiogenesis. J Exp Med. 2010;207:345.

32. Aldhahi W, Hamdy O. Adipokines, inflammation, and the endothelium in diabetes. Current Diabetes Reports. 2003;3:293-8.

33. Furnary AP, Gao G, Grunkemeier GL, Wu Y, Zerr KJ, Bookin SO, et al. Continuous insulin infusion reduces mortality in patients with diabetes undergoing coronary artery bypass grafting. J Thorac Cardiovasc Surg. 2003: 125:1007-21.

34. Iellamo F, Volterrani M, Caminiti G, Karam R, Massaro R, Fini M, et al Testosterone therapy in women with chronic heart failure: a pilot doubleblind, randomized, placebo-controlled study. J Amer Coll Cardiol. 2010;56: 1310-6.

35. Vegunta S, Kling JM, Kapoor E. Androgen Therapy in Women. J Women's Health. 2019.

36. Zhao D, Guallar E, Ouyang P, Subramanya V, Vaidya D, Ndumele CE, et al. Endogenous sex hormones and incident cardiovascular disease in postmenopausal women. J Amer Coll Cardiol. 2018;71:2555-66.

37. Lucas-Herald AK, Alves-Lopes R, Montezano Augusto C, Ahmed SF, Touyz RM. Genomic and non-genomic effects of androgens in the cardiovascular system: clinical implications. Clin Sci. 2017;131:1405-18.

38. Usselman CW, Yarovinsky TO, Steele FE, Leone CA, Taylor HS, Bender JR, et al. Androgens drive microvascular endothelial dysfunction in women with polycystic ovary syndrome: role of the endothelin B receptor. J Physiol. 2019:597:2853-65.

39. Wenner MM, Taylor HS, Stachenfeld N. Endothelin B receptor contribution to peripheral microvascular function in women with polycystic ovary syndrome. J Physiol. 2011;589(19):4671-9.

40. Wenner MM, Taylor HS, Stachenfeld NS. Androgens influence microvascular dilation in PCOS through ET-A and ET-B receptors. Amer J Physiol Endocrinol Metab. 2013;305:E818-E25

41. Shorakae S, Ranasinha S, Abell S, Lambert G, Lambert E, de Courten B, et al. Inter-related effects of insulin resistance, hyperandrogenism, sympathetic dysfunction and chronic inflammation in PCOS. Clin Endocrinol. 2018;89: 628-33.

42. Kravariti M, Naka KK, Kalantaridou SN, Kazakos N, Katsouras CS, Makrigiannakis A, et al. Predictors of endothelial dysfunction in young 
women with polycystic ovary syndrome. J Clin Endocrinol Metab. 2005;90: 5088-95.

43. Azziz R, Carmina E, Dewailly D, Diamanti-Kandarakis E, Escobar-Morreale HF, Futterweit W, et al. The androgen excess and PCOS society criteria for the polycystic ovary syndrome: the complete task force report. Fertil Steril. 2009; 91:456-88.

44. Anderson SA, Barry JA, Hardiman PJ. Risk of coronary heart disease and risk of stroke in women with polycystic ovary syndrome: a systematic review and meta-analysis. Int J Cardiol. 2014;176:486-7.

45. McCrohon JA, Jessup W, Handelsman DJ, Celermajer DS. Androgen exposure increases human monocyte adhesion to vascular endothelium and endothelial cell expression of vascular cell adhesion molecule-1. Circulation. 1999:99:2317-22.

46. Paradisi G, Steinberg HO, Hempfling A, Cronin J, Hook G, Shepard MK, et al. Polycystic ovary syndrome is associated with endothelial dysfunction. Circulation. 2001;103:1410-5.

47. Bajuk Studen K, Šebeštjen M, Pfeifer M, Preželj J. Influence of spironolactone treatment on endothelial function in non-obese women with polycystic ovary syndrome. Eur J Endocrinol. 2011;164:389-95.

48. Gulanski BI, Flannery CA, Peter PR, Leone CA, Stachenfeld NS. Compromised endothelial function in transgender men taking testosterone. Clin Endocrinol. 2020;92:138-44.

49. Kelly DM, Jones TH. Testosterone: a vascular hormone in health and disease J Endocrinol. 2013;217:R47-71.

50. Wild RA, Carmina E, Diamanti-Kandarakis E, Dokras A, Escobar-Morreale HF, Futterweit $W$, et al. Assessment of cardiovascular risk and prevention of cardiovascular disease in women with the polycystic ovary syndrome: a consensus statement by the androgen excess and polycystic ovary syndrome (AE-PCOS) society. J Clin Endocrinol Metab. 2010;95:2038-49.

51. Yanagisawa M, Kurihara H, Kimura S, Tomobe Y, Kobayashi M, Mitsui Y, et al. A novel potent vasoconstrictor peptide produced by vascular endothelial cells. Nature. 1988:332:411-5.

52. Inoue A, Yanagisawa M, Kimura S, Kasuya Y, Miyauchi T, Goto K, et al. The human endothelin family: three structurally and pharmacologically distinct isopeptides predicted by three separate genes. Proc Natl Acad Sci USA. 1989;86:2863-7.

53. Diamanti-Kandarakis E, Spina G, Kouli C, Migdalis I. Increased endothelial-1 levels in women with polycystic ovary syndrome and the beneficial effect of metformin therapy. J Clin Endocrinol Metab. 2001;86:4666-73.

54. Stachenfeld NS, Yeckel CW, Taylor HS. Greater exercise sweating in obese women with polycystic ovary syndrome compared with obese controls. Med Sci Sports Exerc. 2010;42:1660-8.

55. Gui J, Wang R-H. Cardiovascular autonomic dysfunction in women with polycystic ovary syndrome: a systematic review and meta-analysis. Reprod BioMed Online. 2017;35:113-20.

56. Hashim ZH, Hamdan FB, Al-Salihi AR. Autonomic dysfunction in women with polycystic ovary syndrome. Iran J Reprod Med. 2015;13:27-34.

57. Kuppusamy S, Pal GK, Habeebullah S, Ananthanarayanan PH, Pal P. Association of sympathovagal imbalance with cardiovascular risks in patients with polycystic ovary syndrome. Endocr Res. 2015;40:37-43.

58. Lansdown A, Rees DA. The sympathetic nervous system in polycystic ovary syndrome: a novel therapeutic target? Clin Endocrinol. 2012;77:791-801.

59. Adkisson EJ, Casey DP, Beck DT, Gurovich AN, Martin JS, Braith RW. Central, peripheral and resistance arterial reactivity: fluctuates during the phases of the menstrual cycle. Exp Biol Med. 2010;235:111-8.

60. Sverrisdottir YB, Mogren T, Kataoka J, Janson PO, Stener-Victorin E. Is polycystic ovary syndrome associated with high sympathetic nerve activity and size at birth? Am J Physiol Endocrinol Metab. 2008;294:E576-81.

61. Lambert EA, Teede H, Sari Cl, Jona E, Shorakae S. Woodington K, et al. Clin Endocrinol (Oxf): Sympathetic activation and endothelial dysfunction in polycystic ovary syndrome are not explained by either obesity or insulin resistance; 2015

62. Moravek MB. Gender-affirming hormone therapy for transgender men. Clin Obstet Gynecol. 2018;61:687-704.

63. Flores AHJ, Gates GJ, Brown TNT. How many adults identify as transgender in the United States? Los Angeles: The Williams Institute; 2016.

64. WPATH. WPATH Clarification on Medical Necessity of Treatment, Sex Reassignment, and Insurance Coverage for Transgender and Transsexual People Worldwide. 2014.
65. Medicine lo. The Health of Lesbian, Gay, Bisexual, and Transgender People: Building a Foundation for Better Understanding. Washington, DC: Institute of Medicine; 2011

66. Maraka S, Singh Ospina N, Rodriguez-Gutierrez R, Davidge-Pitts CJ, Nippoldt $T B$, Prokop $L$, et al. Sex steroids and cardiovascular outcomes in transgender individuals: a systematic review and meta-analysis. J Clin Endocrinol Metab. 2017;102:3914-23.

67. Streed CG Jr, Harfouch O, Marvel F, Blumenthal RS, Martin SS, Mukherjee M. Cardiovascular disease among transgender adults receiving hormone therapy: a narrative review. Ann Intern Med. 2017;167:256-67.

68. Polderman KH, Stehouwer CD, van Kamp GJ, Dekker GA, Verheught FWA, Gooren LG. Influence of sex hormones on plasma endothelin levels. Ann Intern Med. 1993;1995.

69. Irwig MS. Cardiovascular health in transgender people. Rev Endocr Metab Disord. 2018.

70. Quiros C, Patrascioiu I, Mora M, Aranda GB, Hanzu FA, Gomez-Gil E, et al. Effect of cross-sex hormone treatment on cardiovascular risk factors in transsexual individuals. Experience in a specialized unit in Catalonia. Endocrinol Nutr. 2015;62:210-6.

71. Emi Y, Adachi M, Sasaki A, Nakamura Y, Nakatsuka M. Increased arterial stiffness in female-to-male transsexuals treated with androgen. J Obstet Gynaecol Res. 2008;34:890-7.

72. Colizzi M, Costa R, Scaramuzzi F, Palumbo C, Tyropani M, Pace V, et al. Concomitant psychiatric problems and hormonal treatment induced metabolic syndrome in gender dysphoria individuals: a 2 year follow-up study. J Psychosom Res. 2015;78:399-406.

73. Wierckx K, Van Caenegem E, Schreiner T, Haraldsen I, Fisher AD, Toye K, et al. Cross-sex hormone therapy in trans persons is safe and effective at short-time follow-up: results from the European network for the investigation of gender incongruence. J Sex Med. 2014;11:1999-2011.

74. Elbers JM, Giltay EJ, Teerlink T, Scheffer PG, Asscheman H, Seidell JC, et al. Effects of sex steroids on components of the insulin resistance syndrome in transsexual subjects. Clin Endocrinol. 2003;58:562-71.

75. Benjamin Emelia J, Muntner P, Alonso A, Bittencourt Marcio S, Callaway Clifton W, Carson April P, et al. Heart disease and stroke statistics-2019 update: a report from the American Heart Association. Circulation. 2019;139: e56-e528.

76. Thijssen DH, Black MA, Pyke KE, Padilla J, Atkinson G, Harris RA, et al. Assessment of flow-mediated dilation in humans: a methodological and physiological guideline. Am J Physiol Heart Circ Physiol. 2011;300:H2-12.

77. Anderson JL, May HT, Lappé DL, Bair T, Le V, Carlquist JF, et al. Impact of testosterone replacement therapy on myocardial infarction, stroke, and death in men with low testosterone concentrations in an integrated health care system. Am J Cardiol. 2016;117:794-9.

78. Traish AM. Benefits and health implications of testosterone therapy in men with testosterone deficiency. Sex Med Rev. 2018;6:86-105.

79. Palmisano BT, Zhu L, Eckel RH, Stafford JM. Sex differences in lipid and lipoprotein metabolism. Molecular Metabolism. 2018;15:45-55.

80. Chandra P, Basra SS, Chen TC, Tangpricha V. Alterations in lipids and adipocyte hormones in female-to-male transsexuals. Int J Endocrinol. 2010; 2010.

81. Elamin MB, Garcia MZ, Murad MH, Erwin PJ, Montori VM. Effect of sex steroid use on cardiovascular risk in transsexual individuals: a systematic review and meta-analyses. Clin Endocrinol. 2010;72:1-10.

82. Maraka S, Singh ON, Rodriguez-Gutierrez R, Davidge-Pitts CJ, Nippoldt TB, Prokop $L$, et al. Sex steroids and cardiovascular outcomes in transgender individuals: a systematic review and meta-analysis. The Journal of Clinical Endocrinology \& Metabolism. 2017;102:3914-23.

83. Wild RA, Applebaum-Bowden D, Demers LM, Bartholomew M, Landis JR, Hazzard WR, et al. Lipoprotein lipids in women with androgen excess: independent associations with increased insulin and androgen. Clin Chem. 1990;36:283.

\section{Publisher's Note}

Springer Nature remains neutral with regard to jurisdictional claims in published maps and institutional affiliations. 